\title{
17-Hydroxyprogesterone Caproate for the Prevention of Recurrent Preterm Birth - A Systematic Review and Meta-analysis Taking into Account the PROLONG Trial
}

\section{7-Hydroxyprogesteroncaproat zur Prävention der wiederholten Frühgeburt - systematische Übersicht und Metaanalyse unter Berücksichtigung des PROLONG-Trials}

\section{(c) (1) $\Theta$}

Authors

Ruben-J. Kuon ${ }^{1}$, Richard Berger ${ }^{2}$, Werner Rath ${ }^{3}$

\author{
Affiliations \\ 1 Universitätsklinikum Heidelberg, Abteilung für Gynäko- \\ logische Endokrinologie und Fertilitätsstörungen, \\ Frauenklinik, Heidelberg, Germany \\ 2 Marienhausklinikum, Frauenklinik, Neuwied, Germany \\ 3 Medizinische Fakultät Gynäkologie und Geburtshilfe, \\ Universitätsklinikum Schleswig-Holstein, Campus Kiel, \\ Kiel, Germany
}

Key words preterm birth, progesterone, $17 \alpha$-hydroxyprogesterone caproate, prevention

\section{Schlüsselwörter}

Frühgeburt, Progesteron, 17- $\alpha$-Hydroxyprogesteroncaproat, Prävention

received

accepted after revision

18. 10.2020

Bibliography

Geburtsh Frauenheilk 2021; 81: 61-69

DOI 10.1055/a-1295-0752

ISSN 0016-5751

(c) 2021. The Author(s).

This is an open access article published by Thieme under the terms of the Creative Commons Attribution-NonDerivative-NonCommercial-License, permitting copying and reproduction so long as the original work is given appropriate credit. Contents may not be used for commercial purposes, or adapted, remixed, transformed or built upon. (https://creativecommons.org/licenses/by-nc-nd/4.0/)

Georg Thieme Verlag KG, Rüdigerstraße 14,

70469 Stuttgart, Germany

\author{
Correspondence \\ Privatdozent Dr. med. Ruben-J. Kuon \\ Universitätsklinikum Heidelberg, Abteilung für Gynäkologi- \\ sche Endokrinologie und Fertilitätsstörungen, Frauenklinik, \\ Heidelberg \\ Im Neuenheimer Feld 440, 69120 Heidelberg, Germany \\ Ruben.Kuon@med.uni-heidelberg.de \\ E \\ Deutsche Version unter: \\ https://doi.org/10.1055/a-1295-0752
}

\section{ABSTRACT}

Background Prior spontaneous preterm birth is a strong risk factor for the recurrence of spontaneous preterm birth in a subsequent pregnancy and has been evaluated in prevention studies using progesterone (natural progesterone administered orally or vaginally, and 17-hydroxyprogesterone caproate [17-OHPC]) as a selection criterion. Based on the findings of a randomized, placebo-controlled study, 17-OHPC was approved for use in 2011 by the Food and Drug Administration in the USA for the prevention of recurrent preterm birth. The approval was granted with qualification that a subsequent confirmatory study would need to be carried out, the results of which have just been published (PROLONG trial).

Method A systematic literature search for the period from 1970 to April 2020 using the search terms "preterm birth" and "17-OHPC" or "progesterone" was carried out. Only randomized, placebo-controlled studies of women with singleton pregnancies who received 17-OHPC to prevent recurrent preterm birth were included in the subsequent meta-analysis. The relative risk and associated 95\% confidence intervals were calculated. The heterogeneity between studies was evaluated with $I^{2}$ statistics.

Results In addition to the original study used for the approval and the PROLONG trial, only one other study was found which met the inclusion criteria (total number of patients: 2221). 
With considerable heterogeneity between the studies, particularly with respect to the risk factors for preterm birth, the comparison between 17-OHPC and placebo showed no significant reduction in preterm birth rates before 37, 35 and 32 weeks of gestation and no significant differences with regard to the prevalence of miscarriage before 20 weeks of gestation or fetal deaths (antepartum or intrapartum) after 20 weeks of gestation and neonatal morbidity.

Conclusion Based on the currently available data, 17-OHPC cannot be recommended for the prevention of recurrent preterm birth. Further randomized, placebo-controlled studies with clearly defined, comparable risk factors are required to identify the group of pregnant women which could benefit from the use of 17-OHPC to prevent preterm birth.

\section{ZUSAMMENFASSUNG}

Hintergrund Die vorangegangene spontane Frühgeburt gilt als starker Risikofaktor für eine erneute Frühgeburt in der Folgeschwangerschaft und wurde in Präventionsstudien mit Progesteron (natürliches Progesteron oral oder vaginal, sowie 17-Hydroxyprogesteroncaproat [17-OHPC]) als Selektionskriterium evaluiert. Basierend auf einer randomisierten, placebokontrollierten Studie wurde 17-OHPC 2011 von der Food and Drug Administration in den USA zur Prävention der wiederholten Frühgeburt zugelassen mit der Vorgabe einer folgenden konfirmatorischen Studie, die soeben publiziert wurde (PROLONG-Trial).
Methode Es wurde eine systematische Literaturrecherche des Zeitraumes 1970 bis April 2020 mit den Suchbegriffen Frühgeburt und 17-OHPC oder Progesteron durchgeführt. Eingeschlossen in die folgende Metaanalyse wurden nur randomisierte, placebokontrollierte Studien bei Frauen mit Einlingsschwangerschaft, die 17-OHPC zur Prävention der wiederholten Frühgeburt erhielten. Das relative Risiko und die dazu gehörigen 95\%-Konfidenzintervalle wurden berechnet. Die Heterogenität zwischen den Studien wurde mit der I $^{2}$-Statistik bewertet.

Ergebnisse Neben der Studie, die zur Zulassung führte und dem PROLONG-Trial, liegt lediglich eine weitere Studie vor, die die Einschlusskriterien erfüllt (Gesamtzahl der Patientinnen: 2221). Bei erheblicher Heterogenität zwischen den Studien vor allem bezüglich der Risikofaktoren für Frühgeburt zeigte sich beim Vergleich von 17-OHPC versus Placebo keine signifikante Reduktion der Frühgeburtenraten vor 37, 35 und 32 SSW sowie keine signifikanten Unterschiede bezüglich der Häufigkeit an Fehlgeburten vor 20 SSW und fetalen Toden (antepartal oder intrapartal) nach 20 SSW und der neonatalen Morbidität.

Schlussfolgerung Nach derzeitiger Datenlage kann 17 OHPC nicht zur Prävention der wiederholten Frühgeburt empfohlen werden. Weitere randomisierte, placebokontrollierte Studien mit klar definierten vergleichbaren Risikofaktoren sind erforderlich, um die Schwangeren zu identifizieren, die von der Prävention mit 17-OHPC profitieren könnten.

\section{Introduction}

The global prevalence of preterm birth, depending on the level of medical care available in the respective countries, is between 5$18 \%$; the figure for Germany in 2017 was $8.4 \%$ [1,2]. Preterm birth is responsible for $75 \%$ of cases of perinatal mortality, up to $35 \%$ of cases of neonatal mortality, and $16 \%$ of infant and child deaths below the age of 5 years [2,3]. Extremely preterm birth ( $<28$ weeks of gestation), in particular, is associated with serious neonatal morbidity (e.g., respiratory distress syndrome, necrotizing enterocolitis [NEC], intraventricular hemorrhage [IVH]) and significant long-term neurological deficits in children [4].

Spontaneous preterm birth in a prior pregnancy is a strong independent risk factor for recurrence of preterm birth in a subsequent pregnancy (adjusted odds ratio [aOR]: 3.6; 3.2-4.0) [5]. Depending on the number of prior spontaneous preterm births and the gestational age when they occurred, the absolute risk of recurrence is $30 \%$ and rises to $57 \%$ in cases with two or more previous preterm births which occurred $<32$ weeks of gestation [6].

An effective way of preventing preterm birth is still one of the unresolved problems in obstetrics.

Based on promising results from clinical studies and research findings, the focus of interest has moved to the use of progestins to prevent preterm birth. Progestins inhibit uterine contractions, affect the expression of contraction-promoting proteins such as connexin $43 \mathrm{Ca}^{+}$channels and oxytocin receptors, reduce the production of proinflammatory cytokines and have a significant impact on the biochemical processes and function of the uterine cervix [7-9].

Synthetic 17-OHPC (half-life: 7.8 days) administered intramuscularly or subcutaneously at a dosage of $250 \mathrm{mg}$ or $275 \mathrm{mg} /$ week and progesterone (half-life: 35-55 hours) administered orally (200-400 mg/day) or vaginally (90 mg as a gel, $100-200 \mathrm{mg}$ in a capsule) are used in clinical practice.

The results for vaginal progesterone administered to prevent preterm birth following a previous preterm birth are contradictory (summary given in [10]).

It has become clear in this context that the pregnant women must be carefully selected to identify those who will actually benefit from prevention therapy with progesterone.

The randomized, placebo-controlled study by Meis et al. published in 2003 (Maternal-Fetal Medicine Units [MFMU] trial) was decisive for the FDA approval of 17-OHPC for the prevention of recurrent preterm birth in the USA. Their study reported a significant reduction in preterm birth rates before the 37,35 and 32 weeks of gestation following the intramuscular administration of $250 \mathrm{mg}$ 17-OHPC/week compared to placebo, beginning in weeks $16-20$ of gestation, as well as a significant decrease in the rates of $\mathrm{NEC}, \mathrm{IVH}$ and oxygen administration in the neonates [11].

The not significantly higher rate of miscarriages before 20 weeks of gestation and of fetal deaths (antepartum and intrapartum) after 20 weeks of gestation in the active treatment group has raised concerns about possible, not previously known side effects of 17-OHPC. The study also came under fire [12-14] be- 
cause of the very high rates of preterm births compared to other studies in both the placebo group (54.9\%) and the 17-OHPC arm (36.3\%), which were similar to the rates reported for control groups in other studies $[15,16]$. It was suggested that a possible cause of these high rates could be the potentially uterotonic effect of castor oil, the vehicle used in both the active treatment group and the control group [12].

Even though the US Food and Drug Administration (FDA) usually demands at least two independent clinical studies and the MFMU trial was not planned as a drug approval study, 17-OHPC (preparation: Makena ${ }^{\circledR}$ ) was approved for use by the FDA for the prevention of preterm birth in singleton pregnancies after prior spontaneous preterm singleton births (the approval was given in the form of an accelerated approval [subpart $\mathrm{H}$-accelerated approval of new drugs for serious or life-threatening illnesses]) in 2011. The requirement for this approval was, however, conditional on carrying out a confirmatory study (Progestin's Role in Optimizing Neonatal Gestational Length, PROLONG trial) which would evaluate the efficacy of 17-OHPC with regard to the prevention of preterm birth and reduction of neonatal morbidity as well as different safety aspects and which was planned in consultation with the FDA. The study protocol was essentially comparable to that of the MFMU trial.

The aim was to enrol more than 1700 pregnant women in the study. After a long recruitment period (November 2009 to October 2018 [last study visit]), the results of the study are now available [17]. According to the specifications of FDA, at least $10 \%$ of all test subjects had to be recruited in the USA.

The current German guideline "Prevention and Therapy of Preterm Birth” (AWMF registry number 015-025), which was prepared and released prior to the publication of the PROLONG trial, gives an open non-binding recommendation ("may") on the administration of 17-OHPC to women with singleton pregnancies and a history of spontaneous preterm birth [18].

The aim of this review was to examine, based on the newly published data of the PROLONG trial and other suitable studies, to what extent a re-evaluation of the administration of 17-OHPC for the prevention of preterm birth is necessary.

\section{Material and Method}

A literature search was carried out in PubMed for the period 1970 to April 2020. The following search terms were used: preterm ("preterm birth" or "premature birth") and 17-OHPC ("17-alphahydroxyprogesterone”, "17 hydroxyprogesterone”, “caproate”) or progesterone ("progesterone"), and the search focused on randomized controlled studies and English-language and Germanlanguage full-text publications. The aim was to include all randomized, placebo-controlled studies on 17-OHPC treatment for the prevention of preterm birth in women with singleton pregnancies and a history of at least one previous spontaneous preterm birth in the data analysis. The last search was carried out on 30th April 2020.

The endpoints of the meta-analysis were preterm birth before 37,35 and 32 weeks of gestation, the incidence of NEC, IVH grade 3 or 4 , miscarriage $<20$ weeks of gestation and fetal death (antepartum or intrapartum) $>20$ weeks of gestation.
Other possible indications and the use of other progestins, e.g., the use of natural progesterone, were not evaluated. We refer here to recent publications by our group $[10,19]$. The meta-analysis was carried out using Review Manager software (Review Manager [RevMan] Version 5.3. Copenhagen: The Nordic Cochrane Centre, The Cochrane Collaboration, 2014). The relative risk and the associated $95 \%$ confidence intervals were calculated. The heterogeneity of the treatment effect was evaluated using $\mathrm{I}^{2}$ statistics [20]. The results of individual studies were summarized using a fixed-effects model if no substantial statistical heterogeneity was present $\left(\mathrm{I}^{2} \leq 30 \%\right)$. If $\mathrm{I}^{2}$ was $>30 \%$, a random-effects model was used, as recommended in the Cochrane Handbook for Systematic Reviews of Interventions [21].

\section{Results}

\section{Randomized placebo-controlled studies on the prevention of preterm birth using 17-OHPC in women with singleton pregnancy and a history of spontaneous preterm birth}

The literature search using the above-listed search criteria found a total of 2188 publications. When the inclusion criterion "randomized placebo-controlled studies on treatment with 17-OHPC to prevent preterm birth in women with singleton pregnancy and a history of at least one previous spontaneous preterm birth" was applied, a study from Egypt was identified (Ibrahim et al., 2010 [22]), in addition to the study by Meis et al. (MFMU trial) from 2003 and the planned confirmation study by Blackwell et al. (PROLONG trial).

No other randomized placebo-controlled studies examining the administration of 17-OHPC to prevent preterm birth in singleton pregnancies in women with a history of preterm birth were found. Table 1 shows the respective number of patients included in the studies, the inclusion criteria, the type of progestogen, the doses and period of administration, the number of recruiting centers and the primary outcome criteria.

The study by Saghafi et al. was not included as it was not placebo-controlled [23]. The study by Berghella et al. was also not taken into account as it was a secondary analysis of a cerclage study and, in addition to previous preterm birth, had a cervical length of $<25$ as an additional inclusion criterion [24]).

\section{Patient characteristics}

The study by Ibrahim et al. lacked any detailed description of patient characteristics, which can therefore not be included. The only information provided was: 17-OHPC group vs. placebo group: age: $25.32 \pm 4.15$ vs. $25.60 \pm 3.85$ years ( $p>0.05)$; pregnancy: $3.96 \pm 1.06$ vs. $4.08 \pm 0.997$ ( $p>0.05)$.

The patient characteristics for the MFMU and the PROLONG trial are presented in detail in $>$ Table 2 . The patients in the PROLONG trial were recruited across a total of 93 centers in nine different countries.

There were considerable differences between the two studies with regard to risk profiles for preterm birth, including BMI levels, percentage of pregnant women with $>1$ prior preterm birth, time (gestational age) of previous preterm birth, and nicotine and alco- 
Table 1 Randomized placebo-controlled studies: 17-OHPC for the prevention of preterm birth in women with singleton pregnancy and prior preterm birth.

\begin{tabular}{|c|c|c|c|c|c|c|c|c|}
\hline Author & Year & $\begin{array}{l}\text { Number of patients } \\
\text { (17 } \alpha-\mathrm{OHPC} \\
\text { vs. control) }\end{array}$ & $\begin{array}{l}\text { Inclusion } \\
\text { criteria }\end{array}$ & $\begin{array}{l}\text { Type of } \\
\text { gestagen }\end{array}$ & $\begin{array}{l}\text { Dosage and } \\
\text { interval }\end{array}$ & $\begin{array}{l}\text { Period of } \\
\text { administration } \\
(\mathrm{GW})\end{array}$ & $\begin{array}{l}\text { Number of } \\
\text { centers }\end{array}$ & Primary outcome \\
\hline Meis et al. & 2003 & 310 vs. 153 & $\begin{array}{l}\text { prior SPB } \\
\text { (singleton) }\end{array}$ & $\begin{array}{l}\text { i. m. } \\
\text { 17-OHPC }\end{array}$ & $\begin{array}{l}250 \mathrm{mg} \\
\text { per week }\end{array}$ & $16-20$ to 36 & 19 & $\mathrm{~PB}<37 \mathrm{GW}$ \\
\hline $\begin{array}{l}\text { Ibrahim } \\
\text { et al. }\end{array}$ & 2010 & 25 vs. 25 & $\begin{array}{l}\text { prior SPB } \\
\text { (singleton) }\end{array}$ & $\begin{array}{l}\text { i. m. } \\
\text { 17-OHPC }\end{array}$ & $\begin{array}{l}250 \mathrm{mg} \\
\text { per week }\end{array}$ & 2nd trimester to 36 & 1 & $\begin{array}{l}\text { GW at birth, } \\
\mathrm{PB}<37 \mathrm{GW}\end{array}$ \\
\hline $\begin{array}{l}\text { Blackwell } \\
\text { et al. }\end{array}$ & 2019 & 1130 vs. 578 & $\begin{array}{l}\text { prior SPB } \\
\text { (singleton) }\end{array}$ & $\begin{array}{l}\text { i. m. } \\
\text { 17-OHPC }\end{array}$ & $\begin{array}{l}250 \mathrm{mg} \\
\text { per week }\end{array}$ & $16-20$ to 36 & $\begin{array}{l}93 \text { (41 USA, } \\
52 \text { non-USA) }\end{array}$ & $\begin{array}{l}\mathrm{PB}<35 \mathrm{GW} \text {, com- } \\
\text { posite neonatal } \\
\text { morbidity and } \\
\text { mortaility index }\end{array}$ \\
\hline
\end{tabular}

GW: weeks of gestation, i. m.: intramuscular application, 17-OHPC: 17-hydroxyprogesterone caproate, PB: preterm birth, SPB: spontaneous preterm birth, ${ }^{a}$ Compilation of neonatal deaths, grade 3 or 4 intraventricular hemorrhage, infant respiratory distress syndrome, bronchopulmonary dysplasia, necrotizing enterocolitis, confirmed sepsis.

- Table 2 Patient characteristics reported by Meis et al. (2003, MFMU) vs. Blackwell et al. (2019, PROLONG).

\begin{tabular}{|c|c|c|c|c|}
\hline & \multicolumn{2}{|l|}{ MFMU } & \multicolumn{2}{|l|}{ PROLONG } \\
\hline & $17-\mathrm{OHPC}(\mathrm{n}=310)$ & Placebo $(n=153)$ & 17-OHPC $(n=1130)$ & Placebo $(n=578)$ \\
\hline Age (years) & $26.0 \pm 5.6$ & $26.5 \pm 5.4$ & $30.0 \pm 5.2$ & $29.9 \pm 5.2$ \\
\hline BMI prior to pregnancy & $26.9 \pm 7.9$ & $26.0 \pm 7.0$ & $23(21-27)$ & $23(21-27)$ \\
\hline$>1$ previous preterm birth (\%) & 27.7 & 41.2 & 13.1 & 12.1 \\
\hline $\begin{array}{l}\text { Gestational age when the previous } \\
\text { preterm birth occurred (weeks) }\end{array}$ & $30.6 \pm 4.6$ & $31.3 \pm 4.2$ & $32(28-35)$ & $33(29-35)$ \\
\hline \multicolumn{5}{|l|}{ Ethnicity (\%) } \\
\hline - Black & $59.0^{\mathrm{a}}$ & $58.8^{\mathrm{a}}$ & 6.5 & 7.1 \\
\hline - Caucasian & $25.5^{\mathrm{b}}$ & $22.2^{\mathrm{b}}$ & 88.8 & 87.2 \\
\hline - Asian & 0.6 & 0.7 & 2.0 & 3.8 \\
\hline - Hispanic & 13.9 & 17.0 & - & - \\
\hline - Other & 1.0 & 1.3 & 2.7 & 1.9 \\
\hline \multicolumn{5}{|l|}{ Marital status (\%) } \\
\hline - married/living with partner & 51.3 & 46.4 & 89.6 & 90.3 \\
\hline - never married & 38.4 & 41.8 & 7.6 & 6.9 \\
\hline - divorced/widowed/separated & 10.3 & 11.8 & 2.7 & 2.8 \\
\hline Smoking during pregnancy (\%) & 22.6 & 19.6 & 8.1 & 7.1 \\
\hline Alcohol during pregnancy (\%) & 8.7 & 6.5 & 2.1 & 3.1 \\
\hline
\end{tabular}

hol consumption as well as clear differences with regard to ethnicity and marital status.

\section{7-OHPC and the risk of preterm birth}

Preterm birth before 37 weeks of gestation

The three studies included in this analysis reported the rate of preterm births occurring before week 37 of gestation in their patient cohorts. There was no significant difference in the rate of preterm births before 37 weeks of gestation between pregnant women treated with 17-OHPC and those who received placebo ( $\vee$ Fig. 1 a). The $\mathrm{I}^{2}$ statistics show a high level of heterogeneity between the studies [20].

Preterm birth before 35 and 32 weeks of gestation

Only two of the studies provide data on preterm births occurring before week 35 and week 32 of gestation $[11,17]$. There was no significant difference in the rate of preterm births before week 35 and week 32 of gestation between pregnant women treated 


\begin{tabular}{|c|c|c|c|c|c|c|c|c|}
\hline \multirow{3}{*}{$\frac{\text { Study or subgroup }}{\text { Meis } 2003}$} & \multicolumn{2}{|c|}{ 17-ОHPC } & \multicolumn{2}{|c|}{ Placebo } & \multirow[b]{2}{*}{ Weight (\%) } & \multirow{2}{*}{$\begin{array}{c}\text { Risk ratio } \\
\mathrm{M}-\mathrm{H}, \text { random, } 95 \% \mathrm{CI}\end{array}$} & \multirow{2}{*}{\multicolumn{2}{|c|}{$\begin{array}{c}\text { Risk ratio } \\
\mathrm{M}-\mathrm{H} \text {, random, } 95 \% \mathrm{Cl}\end{array}$}} \\
\hline & Events & Total & Events & Total & & & & \\
\hline & 111 & 306 & 84 & 153 & 40.0 & $0.66(0.54,0.81)$ & - & \\
\hline Ibrahim 2010 & 8 & 25 & 13 & 25 & 19.3 & $0.62(0.31,1.22)$ & & - \\
\hline Blackwell 2019 & 257 & 1112 & 125 & 572 & 40.7 & $1.06(0.88,1.28)$ & & $=$ \\
\hline Total $(95 \% \mathrm{Cl})$ & & 1443 & & 750 & 100.0 & $0.79(0.53,1.18)$ & & - \\
\hline Total events & 376 & & 222 & & & & & \\
\hline Heterogeneity: $I^{2}=84 \%$ & & & & & & & $0.5 \quad 0.7$ & $\begin{array}{ll}1.5 & 2.0\end{array}$ \\
\hline Test for overall effect: $Z=$ & $=1.16(\mathrm{p}$ & $.25)$ & & & & & Favours 17-OHPC & Favours placebo \\
\hline
\end{tabular}

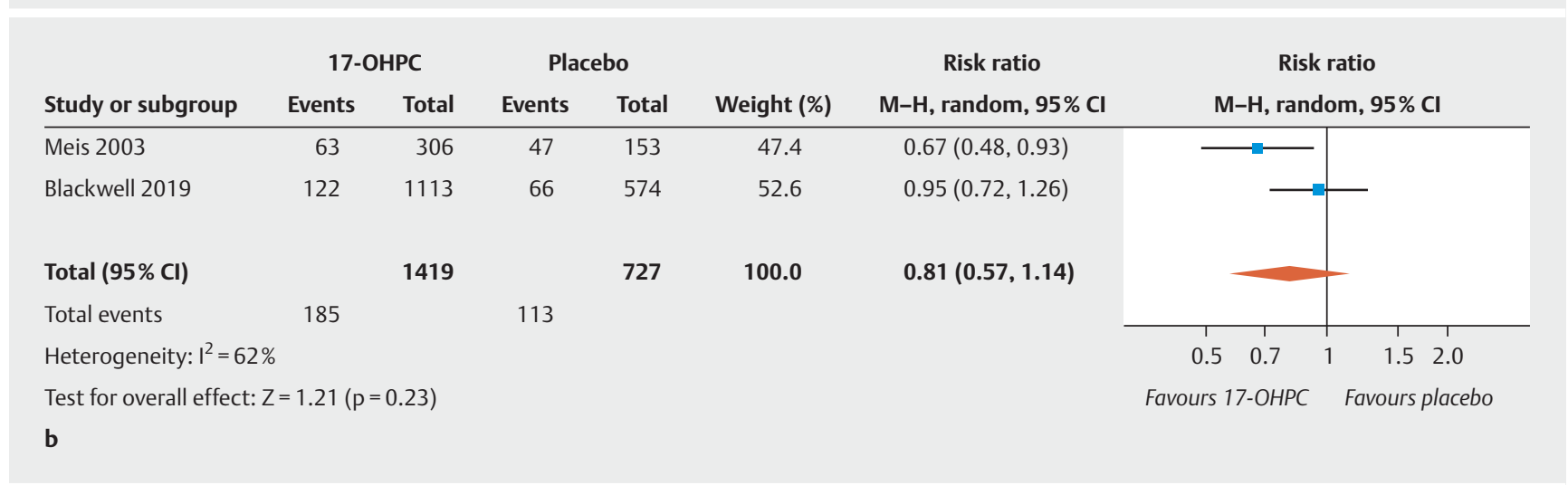

\begin{tabular}{|c|c|c|c|c|c|c|c|c|}
\hline \multirow{3}{*}{$\begin{array}{l}\text { Study or subgroup } \\
\text { Meis } 2003\end{array}$} & \multicolumn{2}{|c|}{ 17-ОНРС } & \multicolumn{2}{|c|}{ Placebo } & \multirow[b]{2}{*}{ Weight (\%) } & \multirow{2}{*}{$\begin{array}{c}\text { Risk ratio } \\
\text { M-H, random, } 95 \% \mathrm{CI}\end{array}$} & \multirow{2}{*}{\multicolumn{2}{|c|}{$\begin{array}{c}\text { Risk ratio } \\
\text { M-H, random, } 95 \% \mathrm{Cl}\end{array}$}} \\
\hline & \multirow{2}{*}{$\frac{\text { Events }}{35}$} & \multirow{2}{*}{$\begin{array}{r}\text { Total } \\
306\end{array}$} & \multirow{2}{*}{$\frac{\text { Events }}{30}$} & \multirow{2}{*}{$\begin{array}{c}\text { Total } \\
153\end{array}$} & & & & \\
\hline & & & & & 49.3 & $0.58(0.37,0.91)$ & $\longrightarrow$ & \\
\hline Blackwell 2019 & 54 & 1116 & 30 & 574 & 50.7 & $0.93(0.60,1.43)$ & & \\
\hline Total (95\% Cl) & & 1422 & & 727 & 100.0 & $0.74(0.47,1.16)$ & 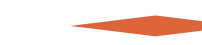 & t \\
\hline Total events & 89 & & 60 & & & & & \\
\hline Heterogeneity: $\left.\right|^{2}=539$ & & & & & & & $0.5 \quad 0.7$ & $1.5 \quad 2.0$ \\
\hline Test for overall effect: & $=1.32(\mathrm{p}$ & .19) & & & & & Favours 17-OHPC & Favours placebo \\
\hline
\end{tabular}

- Fig. 1 Comparison of 17-OHPC versus placebo. Outcomes: preterm birth $<37$ weeks of gestation (a), $<35$ weeks of gestation (b), $<32$ weeks of gestation (c). Forest plots of the relative risk and the associated $95 \%$ confidence intervals for preterm birth $<37$ weeks of gestation (a), $<35$ weeks of gestation (b) and < 32 weeks of gestation (c). 17-OHPC: 17-hydroxyprogesterone caproate, Cl: confidence interval.

with 17-OHPC and those who received placebo ( $\bullet$ Fig. $\mathbf{1} \mathbf{b}$ and $\mathbf{c}$ ). The $\mathrm{I}^{2}$ statistics show a moderate heterogeneity between the studies [20].

- Table 3 compares the perinatal outcomes of the MFMU and PROLONG trials. The study by Ibrahim et al. could not be included in the analysis because of insufficient data.

The meta-analysis showed no significant reduction in the incidence of NEC ( $\triangleright$ Fig. 2 a; low to moderate heterogeneity [20]). The PROLONG trial only reported the rate of infants with grade 3 or $4 \mathrm{IVH}$, so that a meta-analysis could only be carried out for these levels of IVH. No significant decrease in IVH rates was found
( $\triangleright$ Fig. $\mathbf{2}$ b, no heterogeneity [20]). In the MFMU trial, there was a significant decrease in IVH (of any grade) rates in the 17-OHPC group (1.3\% in the $17-\mathrm{OHPC}$ group vs. $5.2 \%$ in the placebo group; $95 \% \mathrm{Cl}: 0.8-0.82)$. The meta-analysis found no significant differences with regard to the incidence of miscarriage before 20 weeks of gestation and fetal death (antepartum or intrapartum) after 20 weeks of gestation between patients treated with 17-OHPC and those who received placebo ( $\vee$ Fig. 3 a [high level of heterogeneity] and $\mathbf{b}$ [no heterogeneity] [20]). 


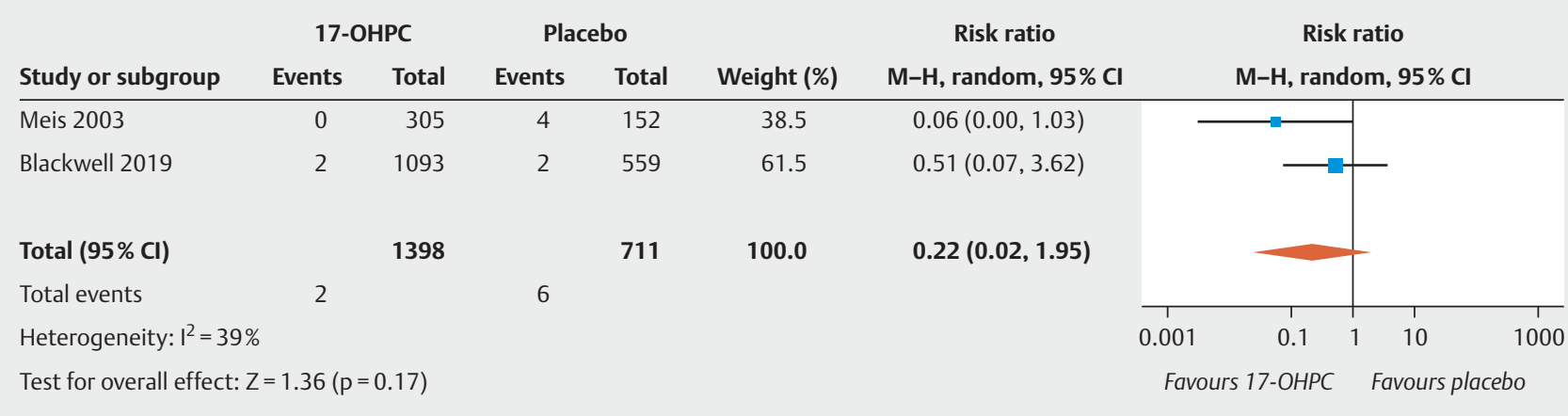

a

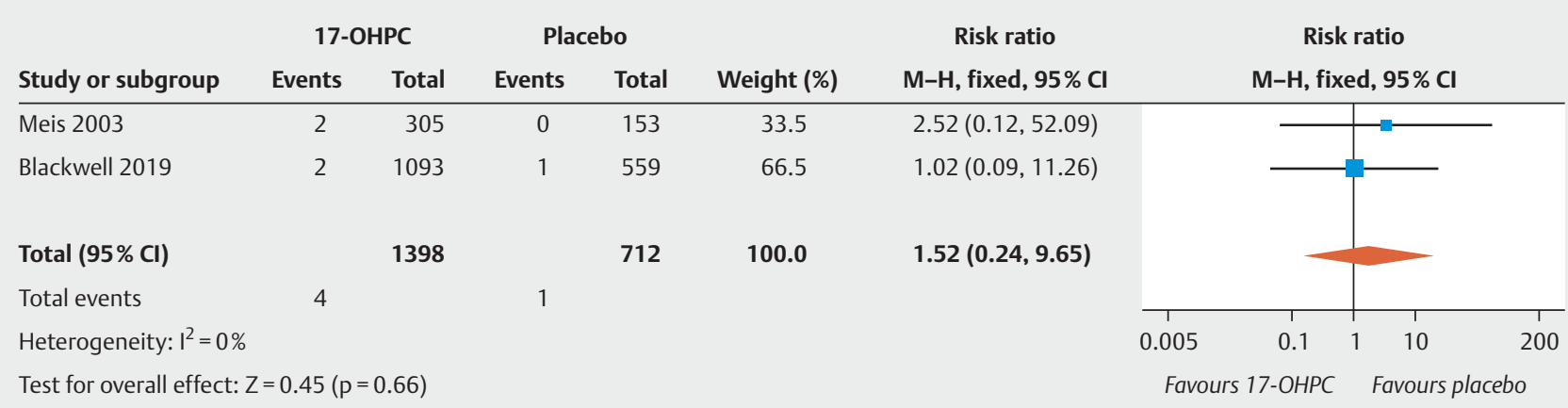

b

- Fig. 2 Comparison of 17-OHPC with placebo. Outcomes: NEC (a), IVH grade 3 or 4 (b). Forest plots for the relative risk and associated 95\% confidence intervals for necrotizing enterocolitis (NEC) (a) and intraventricular hemorrhage (IVH) grade 3 or 4 (b). 17-OHPC: 17-hydroxyprogesterone caproate, $\mathrm{Cl}$ : confidence interval.

- Table 3 Perinatal outcomes in Meis et al. (2003, MFMU) vs. Blackwell et al. (2019, PROLONG).

\begin{tabular}{|c|c|c|c|c|c|c|}
\hline \multirow{2}{*}{ Outcome } & \multicolumn{3}{|l|}{ MFMU } & \multicolumn{3}{|l|}{ PROLONG } \\
\hline & 17-ОНPC (\%) & Placebo (\%) & RR $(95 \% \mathrm{Cl})$ & 17-ОНРC (\%) & Placebo (\%) & RR $(95 \% \mathrm{Cl})$ \\
\hline Birth $<37 \mathrm{GW}$ & 36.3 & 54.9 & $0.66(0.54-0.81)$ & 23.1 & 21.9 & $1.06(0.88-1.28)$ \\
\hline - spontaneous & 29.4 & 45.1 & $0.65(0.51-0.83)$ & 18.8 & 17.1 & $1.10(0.88-1.36)$ \\
\hline - induced & 6.9 & 9.8 & $0.70(0.37-1.32)$ & 4.1 & 4.5 & $0.91(0.57-1.46)$ \\
\hline Birth $<35 \mathrm{GW}$ & 20.6 & 30.7 & $0.67(0.48-0.93)$ & 11.0 & 11.5 & $0.95(0.71-1.26)$ \\
\hline Birth $<32 \mathrm{GW}$ & 11.4 & 19.6 & $0.58(0.37-0.91)$ & 4.8 & 5.2 & $0.92(0.60-1.42)$ \\
\hline Miscarriage $<20 \mathrm{GW}$ & 1.6 & 0 & NA & 0.5 & 1.3 & $0.28(0.08-0.94)$ \\
\hline Antenatal corticosteroids & 17.8 & 19.7 & $0.91(0.60-1.35)$ & 9.3 & 10.6 & $0.88(0.65-1.20)$ \\
\hline Tocolytic therapy & 17.3 & 15.9 & $1.09(0.70-1.69)$ & 11.9 & 10.9 & $1.09(0.82-1.44)$ \\
\hline BPD & 1.3 & 3.3 & $0.40(0.11-1.46)$ & 0.5 & 0.2 & $3.02(0.38-24.1)$ \\
\hline RDS & 9.5 & 15.1 & $0.63(0.38-1.05)$ & 4.9 & 4.7 & $1.06(0.67-1.68)$ \\
\hline NEC & 0 & 2.6 & NA & 0.2 & 0.4 & $0.5(0.07-3.40)$ \\
\hline Chorioamnionitis & 3.6 & 3.3 & $1.09(0.39-3.09)$ & 0.8 & 0.3 & $2.24(0.48-10.41)$ \\
\hline Retinopathy & 1.6 & 3.3 & $0.50(0.15-1.70)$ & 0.5 & 1.3 & $0.37(0.12-1.16)$ \\
\hline IVH grade 3 or 4 & 0.7 & 0 & NA & 0.2 & 0.2 & $0.99(0.09-10.52)$ \\
\hline Confirmed sepsis & 3.0 & 2.6 & $1.12(0.35-3.58)$ & 0.5 & 0.5 & $0.84(0.20-3.56)$ \\
\hline
\end{tabular}

MFMU: Maternal-Fetal Medicine Units, PROLONG: Progestin's Role in Optimizing Neonatal Gestational Length, 17-OHPC: 17-hydroxyprogesterone caproate, GW: weeks of gestation, BPD: bronchopulmonary dysplasia, RDS: respiratory distress syndrome, NEC: necrotizing enterocolitis, IVH: intraventricular hemorrhage. Data are presented as a percentage (\%) or as relative risk with $95 \%$ confidence intervals. bold $=$ statistical significance 


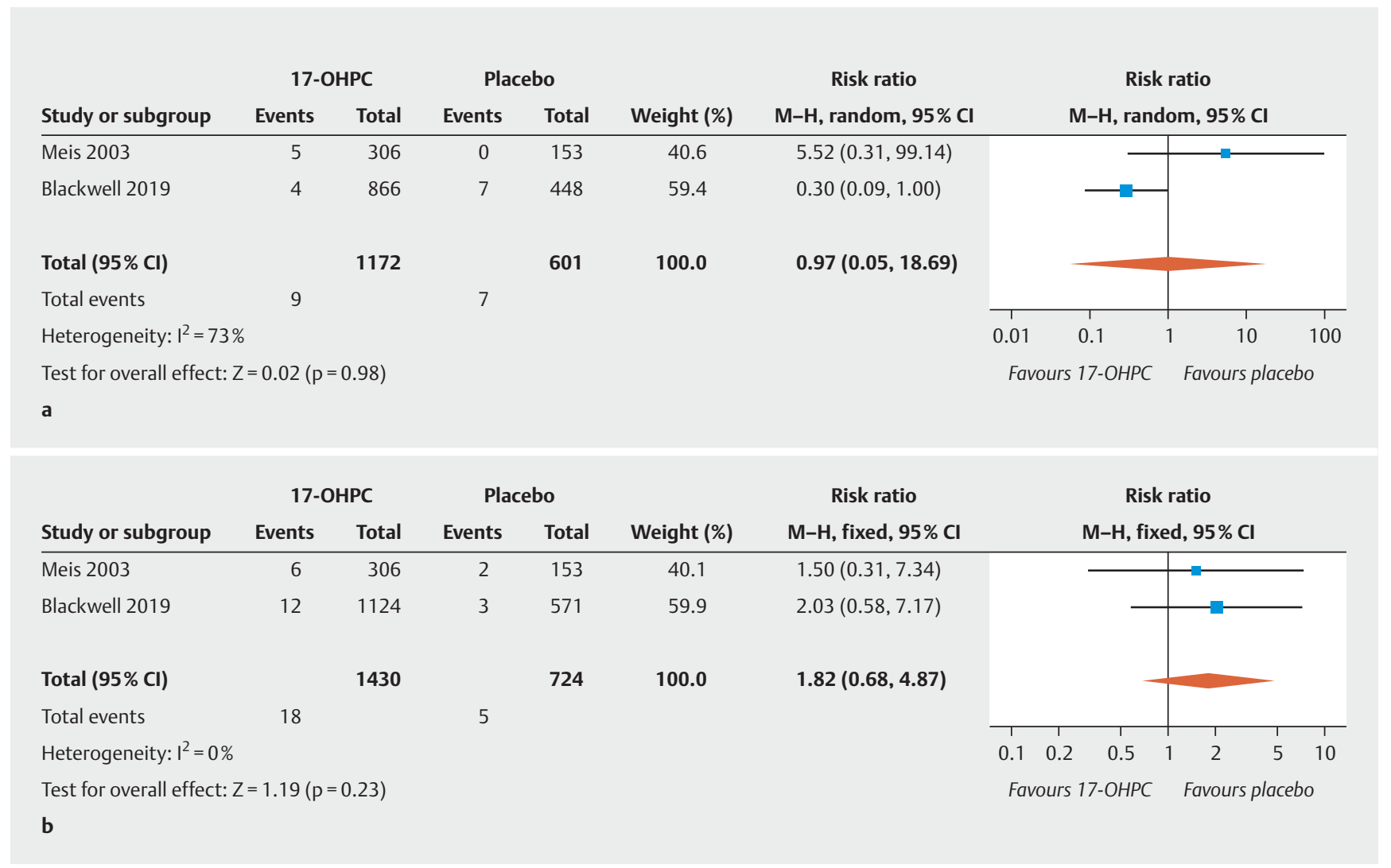

- Fig. 3 Comparison of 17-OHPC with placebo. Outcomes: miscarriage $<20$ weeks of gestation (GW) (a), fetal death (antepartum or intrapartum) $>20 \mathrm{GW}$ (b). Forest plots for the relative risk and associated $95 \%$ confidence intervals for miscarriage $<20 \mathrm{GW}$ (a) and fetal death $>20 \mathrm{GW}$ (antepartum or intrapartum) (b). 17-OHPC: 17-hydroxyprogesterone caproate, Cl: confidence interval.

\section{Discussion}

Preterm birth remains one of the biggest obstetric challenges, as it is associated with high rates of neonatal morbidity and mortality. Strategies to prevent preterm birth are urgently needed, and obstetric research has focused on identifying new strategies.

Spontaneous preterm birth in a previous pregnancy is associated with a 3.6-times higher risk of recurrence of preterm birth in the subsequent pregnancy, meaning that primary prevention is an important issue for these pregnant women [5]. Moreover, the number of prior preterm births and the gestational age when the preterm birth occurred have a significant impact on the risk of recurrent preterm birth [6].

In 2003, Meis et al. published the results of a randomized, placebo-controlled, double-blinded study. In their study, which was carried out across 19 clinics, pregnant women with singleton pregnancies and a history of prior spontaneous preterm birth were randomized in a 2:1 distribution to receive either $250 \mathrm{mg}$ 17-OHPC administered i.m. or placebo, starting in week 16-20 of gestation, and continuing until the birth or week 36 of gestation [11]. Based on previously published data, the authors who planned the study assumed a rate of preterm births before 37 weeks of gestation of $37 \%$ in the control group. The calculated number of cases required to show a $33 \%$ decrease in the rate of preterm births (from 37 to $25 \%$ ) following the administration of
17-OHPC was therefore 500 [11]. The second interim analysis, carried out after the results for around $70 \%$ of included pregnancies were available, showed significant differences in the primary outcome (preterm birth before 37 weeks of gestation), and no further patients were therefore recruited into the study. Their results showed significant decreases in the rate of preterm births occurring before 37 weeks of gestation (from 54.9 to $36.3 \%$ ), before 35 weeks of gestation (from 30.7 to 20.6\%), and before 32 weeks of gestation (from 19.6 to $11.4 \%$ ).

Even though there was a trend indicating that the administration of 17-OHPC was beneficial, our meta-analysis was unable to confirm a significant reduction in the rate of preterm births before 37,35 and 32 weeks of gestation.

Meis et al. explained the extremely high rate of preterm births in the control group (more than $50 \%$ ) by pointing to the almost $30 \%$ of pregnant women who had had more than one prior preterm birth as well as the low gestational age when the preterm birth occurred (around 31 weeks of gestation). In contrast, only every tenth woman in the PROLONG trial $(13.1 \%$ in the $17-\mathrm{OHPC}$ group and $12.1 \%$ in the placebo group) had had more than one previous preterm birth, and preterm births occurred at a later stage of gestation (median: week 32 of gestation in the 17-OHPC group and week 33 of gestation in the placebo group).

This has led to significant differences in the underlying risk for preterm birth (rate of preterm births < 37, 35 and 32 weeks of 
gestation in the placebo group, MFMU trial: 54.9, 30.7, 19.6\% vs. 21.9, 11.5, 5.2\% in the PROLONG trial).

Moreover, the percentage of women in the PROLONG trial who had a cervical length of $<25 \mathrm{~mm}$ (measured prior to the first administration of medication) was lower (less than $2 \%$ ) than that reported in other studies for women with prior preterm birth (e.g., Owen et al., 2009: 318 of 1014 patients with singleton pregnancy and a history of prior preterm birth before 34 weeks of gestation [31\%] had a cervical length of $<25 \mathrm{~mm}$ ) [25-27]. It is assumed that patients with a shortened cervix decided against participating in a placebo-controlled study. Other risk factors for preterm birth were also less prevalent in the patient population of the PROLONG trial (cf. - Table 2). The results of a heterogeneity analysis based on $\mathrm{I}^{2}$ statistics which was carried out in the context of the meta-analysis emphasize the quite high level of heterogeneity between the included studies for the investigated criteria.

Despite the high number of patients included in the study, the authors of the PROLONG trial themselves admit to concerns that, in view of the almost $50 \%$ lower rate of preterm births than expected, the study which aimed to investigate planned primary outcome criteria (decreased rate of preterm births and neonatal outcomes) may have been underpowered [17]. In contrast, the planned number of cases of the MFMU trial was not designed to evaluate differences in neonatal morbidity rates [11].

With regard to neonatal outcomes, the meta-analysis found no reduction in the rate of cases with NEC. The study by Meis et al. reported that the need for additional oxygen in neonates was significantly lower in the 17-OHPC group compared to the placebo group. However, these figures could not be compared in our meta-analysis as the PROLONG trial provides no precise data on this point.

The developmental status of infants exposed to placebo/17OHPC during pregnancy in the context of the PROLONG trial is currently being investigated as part of an ongoing study in which the infants are evaluated when they reach the age of 2325 months.

The pregnant women in the study by Meis et al. were recruited in 19 centers across the USA, and more than $50 \%$ of the pregnant women included in the study were African-American, even though the detected differences were equally significant in the group with a different ethnicity [11]. In the PROLONG trial, $87 \%$ of pregnant women were of Caucasian origin and only $23 \%$ of the test subjects included in the study were from the USA (60\% of the pregnant women were recruited in Russia and Ukraine) [17]. Studies have indicated that the risk of recurrent preterm birth is higher for African-American women compared to women with a different ethnicity; thus, ethnic origin could also be an explanation for the differences in underlying risk [28, 29]. It is therefore possible that pharmacogenomic differences could play a role in the response to 17-OHPC [30].

The noticeable but not significant increase in the rate of miscarriages occurring before 20 weeks of gestation and fetal deaths (antepartum or intrapartum) after 20 weeks of gestation in the 17-OHPC group shown in the study by Meis et al. could not be confirmed in the meta-analysis when the data from the PROLONG trials was examined, refuting safety concerns about this issue.
In a statement on the PROLONG trial, the Society for MaternalFetal Medicine (SMFM) in the USA pointed to the occasionally strongly divergent patient characteristics and associated differences in risk profiles between the studies. The SMFM notes that the study by Meis et al. is the study which has included the largest number of pregnant women from the USA and therefore considers the administration of 17-OHPC to patients with the same characteristics as those from the MFMU trial (i.e., women with a very high risk of recurrent preterm birth) to be reasonable [31]. The SMFM recommends that the risk/benefit assessment for all patients at risk of recurrent preterm birth must include a shared decision-making approach which takes the lack of short-term safety concerns but also the uncertainty regarding benefit into account.

The American College of Obstetricians and Gynecologists (ACOG) has issued a statement concerning the PROLONG trial which also emphasizes the substantial differences between the PROLONG trial and the MFMU trial (ACOG Statement on 17p Hydroxyprogesterone Caproate, October 25, 2019, www.acog.org) and refers to the inadequate statistical power of the PROLONG trial caused by the $50 \%$ lower rate of preterm births, possibly the result of an unintentional selection bias due to a lack of high-risk patients willing to participate in a placebo-controlled study. The ACOG has therefore not changed its existing clinical recommendation that 17-OHPC should be administered to patients with this indication.

\section{Conclusion}

This meta-analysis found no significant benefit in terms of lower preterm birth rates or an improvement in neonatal outcomes following the administration of 17-OHPC starting in weeks 16-20 of gestation and continuing until week 36 of gestation to women with a singleton pregnancy and a history of prior spontaneous preterm birth. More randomized, controlled studies with clearly defined comparable selection criteria are required to identify the specific pregnant women who will benefit from the administration of 17-OHPC to prevent recurrent preterm birth. Based on the data from the MFMU trial and the PROLONG trial, the administration of 17-OHPC for the aforementioned indication is only effective when treating patients with a high risk of recurrent preterm birth, not patients with a low risk of repeat preterm birth. The authors therefore conclude that the open, non-binding recommendation ("may") given in the current AWMF guideline (Prevention and Therapy of Preterm Birth, AWMF registry number 015-025) on administering 17-OHPC to prevent preterm birth in women with a singleton pregnancy and previous spontaneous preterm birth is still valid.

\section{Conflict of Interest}

Ruben-J. Kuon received reimbursements for conference fees and travel costs as well as speaker's fees from Dr. Kade/Besins GmbH. Richard Berger and Werner Rath state that they have no conflict of interest. 


\section{References}

[1] Blencowe H, Cousens S, Chou D et al. Born too soon: the global epidemiology of 15 million preterm births. Reprod Health 2013; 10 (Suppl. 1): S2

[2] IQTIG. Bundesauswertung zum Erfassungsjahr 2017 - Geburtshilfe Qualitätsindikatoren. Accessed August 28, 2019 at: https://iqtig.org/ downloads/auswertung/2017/16n1gebh/QSKH_16n1-GEBH_2017_ BUAW_V02_2018-08-01.pdf

[3] Zeitlin J, Szamotulska K, Drewniak $N$ et al. Preterm birth time trends in Europe: a study of 19 countries. BJOG 2013; 120: 1356-1365

[4] Voss W, Hobbiebrunken E, Ungermann U et al. The Development of Extremely Premature Infants. Dtsch Arztebl Int 2016; 113: 871-878

[5] Murphy DJ. Epidemiology and environmental factors in preterm labour. Best Pract Res Clin Obstet Gynaecol 2007; 21: 773-789

[6] Phillips C, Velji Z, Hanly C et al. Risk of recurrent spontaneous preterm birth: a systematic review and meta-analysis. BMJ Open 2017; 7: e015402

[7] Garfield RE, Saade G, Buhimschi C et al. Control and assessment of the uterus and cervix during pregnancy and labour. Hum Reprod Update 1998; 4: 673-695

[8] Furcron A-E, Romero R, Plazyo O et al. Vaginal progesterone, but not $17 \alpha$-hydroxyprogesterone caproate, has antiinflammatory effects at the murine maternal-fetal interface. Am J Obstet Gynecol 2015; 213: 846.e1-846.e19

[9] Kuon RJ, Shi S-Q, Maul $\mathrm{H}$ et al. Pharmacologic actions of progestins to inhibit cervical ripening and prevent delivery depend on their properties, the route of administration, and the vehicle. Am J Obstet Gynecol 2010; 202: 455.e1-455.e9

[10] Kuon R], Voß P, Rath W. Progesterone for the Prevention of Preterm Birth - an Update of Evidence-Based Indications. Geburtshilfe Frauenheilkd 2019; 79: 844-853

[11] Meis PJ, Klebanoff M, Thom E et al. Prevention of recurrent preterm delivery by 17 alpha-hydroxyprogesterone caproate. N Engl J Med 2003; 348: 2379-2385

[12] lams JD. Was the preterm birth rate in the placebo group too high in the Meis MFMU Network trial of 17-OHPC? Am J Obstet Gynecol 2010; 202: 409-410. doi:10.1016/j.ajog.2010.03.020

[13] Thornton JG. Progesterone and Preterm Labor - Still No Definite Answers. N Engl J Med 2007; 357: 499-501

[14] Greene MF. Progesterone and Preterm Delivery - Déjà Vu All Over Again. N Engl J Med 2003; 348: 2453-2455

[15] lams JD, Newman RB, Thom EA et al. Frequency of uterine contractions and the risk of spontaneous preterm delivery. N Engl J Med 2002; 346: 250-255

[16] Harper M, Thom E, Klebanoff MA et al. Omega-3 fatty acid supplementation to prevent recurrent preterm birth: a randomized controlled trial. Obstet Gynecol 2010; 115 (2 Pt 1): 234-242

[17] Blackwell SC, Gyamfi-Bannerman C, Biggio JR jr. et al. 17-OHPC to Prevent Recurrent Preterm Birth in Singleton Gestations (PROLONG Study): A Multicenter, International, Randomized Double-Blind Trial. Am J Perinatol 2020; 37: 127-136
[18] Berger R, Abele H, Bahlmann $\mathrm{F}$ et al. Prevention and Therapy of Preterm Birth. Guideline of the DGGG, OEGGG and SGGG (S2 k Level, AWMF Registry Number 015/025, February 2019) - Part 1 with Recommendations on the Epidemiology, Etiology, Prediction, Primary and Secondary Prevention of Preterm Birth. Geburtshilfe Frauenheilkd 2019; 79: 800812

[19] Rath W, Kuon RJ. Progesterone - Effective for Tocolysis and Maintenance Treatment After Arrested Preterm Labour?: Critical Analysis of the Evidence. Geburtshilfe Frauenheilkd 2019; 79: 834-843

[20] Higgins JPT, Thompson SG, Deeks JJ et al. Measuring inconsistency in meta-analyses. BMJ 2003; 327: 557-560

[21] Higgins J, Altman D, Sterne J. Chapter 8: Assessing risk of bias in included studies. Cochrane Handbook for Systematic Reviews of Interventions Version 5.1. 0 (updated March 2011). The Cochrane Collaboration; 2011

[22] Ibrahim M, Ramy ARM, Younis MA-F. Progesterone supplementation for prevention of preterm labor: A randomized controlled trial. Middle East Fertil Soc J 2010; 15: 39-41

[23] Saghafi N, Khadem N, Mohajeri T et al. Efficacy of $17 \alpha$-hydroxyprogesterone caproate in prevention of preterm delivery. J Obstet Gynaecol Res 2011; 37: 1342-1345

[24] Berghella V, Figueroa D, Szychowski JM et al. 17-alpha-hydroxyprogesterone caproate for the prevention of preterm birth in women with prior preterm birth and a short cervical length. Am J Obstet Gynecol 2010; 202: 351.e1-351.e6

[25] Owen J, Hankins G, lams JD et al. Multicenter randomized trial of cerclage for preterm birth prevention in high-risk women with shortened midtrimester cervical length. Am J Obstet Gynecol 2009; 201: 375.e1375.e8

[26] lams JD, Goldenberg RL, Meis PJ et al. The length of the cervix and the risk of spontaneous premature delivery. National Institute of Child Health and Human Development Maternal Fetal Medicine Unit Network. N Engl J Med 1996; 334: 567-572

[27] lams JD, Goldenberg RL, Mercer BM et al. The Preterm Prediction Study: recurrence risk of spontaneous preterm birth. National Institute of Child Health and Human Development Maternal-Fetal Medicine Units Network. Am J Obstet Gynecol 1998; 178: 1035-1040. doi:10.1016/s00029378(98)70544-7

[28] Kistka ZA-F, Palomar L, Lee KA et al. Racial disparity in the frequency of recurrence of preterm birth. Am J Obstet Gynecol 2007; 196: 131.e1131.e6

[29] Adams MM, Elam-Evans LD, Wilson HG et al. Rates of and factors associated with recurrence of preterm delivery. JAMA 2000; 283: 1591-1596

[30] Manuck TA, Watkins WS, Moore B et al. Pharmacogenomics of 17-alpha hydroxyprogesterone caproate for recurrent preterm birth prevention. Am J Obstet Gynecol 2014; 210: 321.e1-321.e21

[31] Society for Maternal-Fetal Medicine (SMFM) Publications Committee. SMFM Statement: Use of 17-alpha Hydroxyprogesterone Caproate for Prevention of Recurrent Preterm Birth. Am J Obstet Gynecol 2020; 223: B16-B18 